\title{
Green-Aware Token Based Demand Scheduling for Electricity Markets
}

\author{
Daniel Ngondya, Joseph Mwangoka \\ CoCSE, Nelson Mandela African Institution of Science and Technology, Arusha, Tanzania \\ Email:ngondyad@nm-aist.ac.tz, joseph.mwangoka@nm-aist.ac.t
}

How to cite this paper: Ngondya, D. and Mwangoka, J. (2018) Green-Aware Token Based Demand Scheduling for Electricity Markets. Smart Grid and Renewable Energy, 9, 16-31.

https://doi.org/10.4236/sgre.2018.91002

Received: September 26, 2017

Accepted: January 13, 2018

Published: January 16, 2018

Copyright ( $) 2018$ by authors and Scientific Research Publishing Inc. This work is licensed under the Creative Commons Attribution International License (CC BY 4.0).

http://creativecommons.org/licenses/by/4.0/

(c) (i) Open Access

\begin{abstract}
Increasing consumption, changing nature of loads and the need to reduce carbon emission are some of the factors threatening electricity grid stability and reliability. Demand side management programs mainly work by shifting consumption from peak to off-peak period, which inconveniences some consumers and possibly creates a new peak (Reverse Peak) in off-peak hours. Growing use of Photovoltaic solar power in residences provides an opportunity to manage grid reliability and stability in a more flexible manner, and mitigates reverse peaks. We propose a community based scheduling algorithm that guarantees access to shared power capacity and integrates residences' solar power into the grid. Results indicate peak demand can be reduced by up to $32.1 \%$, while energy costs can be reduced by up to $14.0 \%$. Furthermore, coordinated discharging can mitigate reverse peaks by up to $23.4 \%$. Encouraging and integrating green energy generation and storage in the consumer side is crucial to grid stability and reliability.
\end{abstract}

\section{Keywords}

Token Based Scheduling, Demand Side Management, Solar Power, Green Energy, Reverse Peaks

\section{Introduction}

Traditional Electric Grids are characterized by centralized generation plants, vertically integrated utilities and supply side management of electricity. Traditional grids are showing strains because of recent trends such as deregulation of electricity markets, distributed generation, accommodation of intermittent renewable energy sources, and reduction of air pollution caused by electric grids, Demand Side Management (DSM) and increasing consumption [1] [2] [3] [4] [5]. 
Challenges facing traditional grids have paved the way for Smart Grid vision. Smart grids are characterized by bidirectional flow of information and electricity. Smart grid promises benefits such as improved grid efficiency, resilience, reliability, self-healing ability, demand management, increased consumer choice and possibility of new products, services and markets. For benefits associated with smart grid to be realized, a number of challenges have to be addressed. For instance, smart grid necessitates overhaul of all existing electric meters and replacing them with smart meters which are relatively more expensive. Even appliances will have to be replaced with smart ones-capable of responding to consumer settings and control signals from utilities. It is likely that consumers will be resistant to these changes because of fear of the unknown and privacy. However, factors such as decreasing cost of smart meters and smart appliances, improving access to communication infrastructures and increasing awareness about electricity management means there is a good chance of changes to be embraced by both consumers and utilities [6].

Of main interest to smart grid is DSM of electricity, which provides an opportunity for consumers to respond to various signals from utility companies aimed at ensuring grid stability and reliability [7]. Key idea of DSM programs is to shift consumption from peak hours to off-peak hours. However, if implemented, there is a possibility of creating a new peak during off-peak hours as discussed by [8].

Nature of electricity consumption varies greatly depending on whether a consumer is residential, industrial or commercial. The fact that $40 \%$ of worldwide consumption is attributed to residential consumers has drawn the interest of many researchers [3]. Residential DSM programs can be categorized as either individual based or community based.

Most DSM programs have focused on individual based solutions where scheduling of appliances is done per single residence, whereas in community based solutions, scheduling is done per group of residences. Heterogeneity of consumers in the community may provide further scheduling flexibility that can be exploited by DSM programs.

Growing penetration of Green Energy Sources (GES) in residences as observed by [9] provides additional consumption versatility that can be employed by DSM programs. However, GES’ systems are characterized by intermittency and constraints on storage capacity, therefore it is crucial that they are integrated with electricity grid and access to it is guaranteed for each consumer. In community based DSM programs where power capacity is shared among several residences; guaranteed access to shared capacity is important for consumers' confidence and acceptance of the program. In this paper, we propose a token based green-aware community scheduling program with coordinated storage charging and discharging, aiming at reducing energy cost while taking consumer comfort into account and mitigating reverse peaks.

This paper is organized as follows: Section 2 discusses works related to residential DSM programs. Section 3 presents a definition of the problem. Section 4 
describes a Token based scheduling algorithm. Section 5 studies the token based scheduling algorithm numerically and Section 6 draws conclusions.

\section{Related Works}

DSM denotes programs that allow utilities to plan, implement and monitor their activities so as to shape consumers' electricity consumptions. DSM programs largely work by encouraging consumers to shift some of their tasks from peak to off-peak hours in return for some incentives. Reducing peak demand is in the interest of utilities as it enables them to curtail usage of peak plants which are commonly more expensive compared to base plants, and therefore reduce their running costs and improve reliability of supply. Success of DSM programs necessitates behavior change on the part of consumers as they may be required to change their consumption patterns. It is therefore not expected that all consumers will respond positively to DSM programs, hence raising the need to exploit heterogeneity of consumers [10].

Works by [11] [12] have proposed DSM programs that encourages consumers to shift their consumption from peak-demand to off-peak demand using price incentives. Price is higher during peak-demand and cheaper during off-peak demand. As a result, consumers have an opportunity to reduce their bills by shifting consumption from peak-demand to off-peak demand. In [11], appliances are modeled as finite state machine and an amount of power that each consumer can access is limited. The proposed DSM program can achieve up to $33.3 \%$ peak demand reduction. Work by [12] ensures interests of both utilities and consumers are taken into account when designing prices to encourage shifting of demand from peak-demand to off-peak demand. However, these works do not take into account discomforts that consumers have to face to shift their loads.

In studies by [13] [14] [15] [16] [17], consumer cost minimization and comfort are taken into account as scheduling appliances means possible consumption behavior change. Work by [13] establishes similarity in consumption pattern so as to reduce both cost and scheduling discomfort to the consumer. Delay in running of appliances together with cost reduction has been studied in [14]. Authors in [15] have evaluated willingness of consumers to take part in a proposed DSM program that employs fuzzy technology. The program estimates price responsiveness of consumers to incentives using a rational decision making model. Peak Average Ratio (PAR), cost and waiting time reduction using genetic algorithm have been considered in [16]. Work by [17] considers PAR reduction while avoiding possible reverse peaks using unequal consumer participation rates. Price fairness is also taken into account. Since shifting peak demand (PAR reduction) is likely to be painful for some consumers, further flexibility can be obtained by tapping into increasing use of GES in residences, especially by encouraging consumers to use their GES during peak demand. GES benefits include: lower costs in the long run, provides energy security through diversifica- 
tion, easily accessible to consumers and as an alternative to fossil fuels, it helps reduce carbon emissions [18].

DSM programs equipped with GES and Storage have been considered in [19] [20]. Residences with GES and storage have an opportunity to sell excess power generated to the grid using feed-in tariffs. The tariffs are designed in such a way the utility does not lose out money by setting the selling prices lower than the consumers buying prices. In [19], GES and storage are used to reduce energy cost and scheduling discomfort of the consumer. A disutility function is used to model discomfort and Markov chain based model is used to represent various constraints. Work by [20] provides an opportunity for consumers with storage to sell electricity to the grid while taking into account scheduling discomfort.

All of these works [11]-[17] [19] [20] have scheduled appliances per single residence. Scheduling can also be done per group of residences and therefore be able to schedule multiple appliances at once. Scheduling per group of residences is also called community based scheduling. Some of the benefits of community based scheduling include: reverse peaks can be avoided through load synchronization in the community, allows interaction among community members and therefore they can trade with each other excess locally generated electricity and hence avoid transmission losses, system-wide perspective of community programs enable utilities to exploit consumers' appliance usage diversity to manage peak demand [21] [22] [23].

Community based scheduling DSM programs have been studied in [8] [21] [23] [24] [25] [26]. Work by [21] proposes an autonomous and distributed agent-based DSM program that seeks to minimize energy cost while taking into consideration price fairness among consumers. Observing that DSM programs are sensitive to forecasting errors, work by [26] proposes a DSM program that is robust to forecasting errors by amalgamating consumption of several consumers. Distributed generation and storage are used to reduce scheduling discomfort of consumers during peak hours by [25]. Reference [8] presents a DSM program that considers financial implications of both consumers and utility. The proposed DSM program further mitigates reverse peaks by modeling interactions between utility and consumers as a Stackelberg game with the utility as a leader and a community of consumers as followers. In the game, the leader keeps on modifying prices in order to discourage formation of reverse peaks, until there is no incentive for consumers to respond in such a way that reverse peaks occur. However, constantly changing prices in order to mitigate reverse peaks may sound unfair to some consumers. In [24], a DSM program that minimizes consumer cost and waiting discomfort is proposed. The program coordinates schedule of appliances in the entire community. Residences in the community shares maximum power capacity set by a utility. Residences compete for shared capacity using an algorithm based on random back-off mechanism. Most of the discussed community based scheduling algorithms do not guarantee access to shared capacity for each residence, this increases resistance of consumers to embrace DSM programs. Moreover, power capacity constraints faced by utilities 
has not been addressed in most of the proposed programs which does not reflect realities in developing countries where there generation capacity is largely inadequate.

In this work, we propose a green-aware token based scheduling algorithm that seeks to reduce energy cost of the consumers depending on their comfort settings regarding maximum waiting time of appliances. The algorithm coordinates charging and discharging of storage so that consumers with GES may consume stored energy during peak hours, thereby mitigating reverse peaks.

\section{Problem Definition}

We consider a community of electricity consumers with $\mathrm{N}$ residences, with $\mathrm{n}$ representing a particular residence. The community comprises of several nearby residences connected together by a communication network and to the low voltage side of the distribution network. For privacy reasons, it is assumed that there is no directly communication between residences, except through a Coordinator that can be housed at a transformer unit. We assume every residence in the community is equipped with Smart meters, Smart Appliances, Home Energy Management Units (HEMU). We further assume some residences have Photovoltaic systems with battery storage as illustrated in Figure 1.

Smart meters are used to record electricity consumption, exchange information between utility and consumer, and manage usage by switching on/off some appliances, track consumption over time and schedule appliances [27]. HEMUs provide an interface for a user to track consumption and take necessary optimization decisions. They can also be used to show generation capacity and storage constraints [28]. Smart appliances connect to the smart meter and depending on information received they can shift consumption from peak to off-peak hours [29].

Smart appliances can be categorized into two main groups: Fixed and Elastic appliances. Fixed appliances have stringent time and power requirements and therefore cannot be scheduled. Examples of fixed appliances include: Television, Computer, Lights, etc. Elastic appliances are flexible in terms starting time and power consumption. Examples of elastic appliances are: Dishwasher, Washing machine, Dryer, and Water Heater. Elastic appliances provide an opportunity to

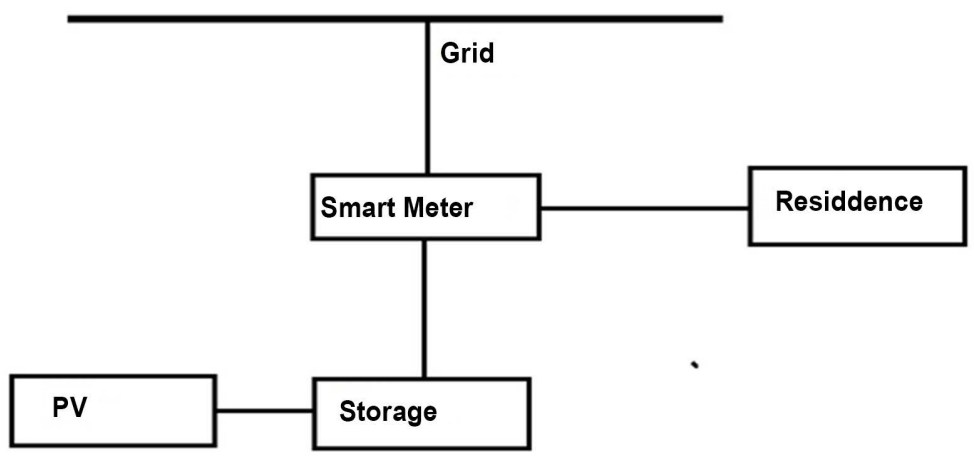

Figure 1. Green-aware system schematic. 
schedule them during off-peak demand so as to reduce peak demand. Use of GES and storage during peak hours helps to overcome scheduling discomfort through self-supply.

There are many forms of GESs, for instance Solar, wind and geothermal energy sources with various technological approaches. Among different technologies available on the market, Photovoltaic (PV) solar powered generation is the commonest, especially in residences [30]. Subsection 3.1 to 3.3 models a residence with PV generation and storage.

\subsection{Solar Power Modeling}

Assuming some residences are installed with one or more PV arrays, hourly generated power is as indicated in Equation (1):

$$
P_{p v, h}^{n}=\eta_{p v} * I_{p v, h} * S_{p v, n} \quad[18][31]
$$

$P_{p v, h}^{n}$ denotes hourly power output(in $\mathrm{kWh}$ ) from consumer $n$ 's PV array(s), $\eta_{p v}$ is the PV system's efficiency in converting solar energy into electric energy, $I_{p v, h}$ is the hourly solar irradiation-power per unit area received from the Sun in the form of electromagnetic radiation, measured in $\mathrm{kWh} / \mathrm{m}^{2}$, and $S_{p v, n}$ represents the size of the PV array(s) in $\mathrm{m}^{2}$.

\subsection{Storage Modeling}

Residences with PV Solar system are additionally connected to battery storage so as to store generated power for use during peak demand. It is assumed the battery storage is charged during the day and used (discharged) at night. For each storage in residence $n$, there are two key constraints that determine how much power can be stored and accessed: minimum capacity $B_{\min , n}$ and maximum capacity $B_{\max , n}$. In between the two constraints is the State of Charge (SOC) which varies depending on whether the storage is being charged or discharged (see Equation (5)). Hourly SOC of residence $\mathrm{n}$ is denoted as $B_{h, n}$. Equation (2) indicates SOC during charging process, where $\eta_{c}$ is the charging efficiency. Based on works of [18] [32] [33]; we formulate Equation (2) to Equation (4) as follows:

$$
B_{h+1, n}=B_{h, n}+\eta_{c} * P_{p v, h}^{n}
$$

Equation (3) indicates SOC during discharge process. $\eta_{d}$ is the discharging efficiency and $l_{n, h}$ is the hourly load at residence $n$.

$$
B_{h+1, n}=B_{h, n}-1 / \eta_{d} * l_{n, h}
$$

Charging and discharging is as indicated in Equation (4). Depth of Discharge (DOD) determines how deeply the storage can be discharged and is bounded between minimum capacity and maximum capacity as indicated in Equation (5).

$$
\begin{gathered}
B_{h+1, n}=B_{h, n}+\eta_{c} * P_{p v, h}^{n}-1 / \eta_{c} * l_{n, h} \\
B_{\min , n} \leq B_{h, n} \leq B_{\max , n} \\
B_{\min , n}=(1-D O D) * B_{\max , n}
\end{gathered}
$$




\subsection{Green-Aware Demand Side Management Model}

Suppose a community has $N$ residences, let $n$ denote particular residence. Let there be $H$ scheduling slots in a day, where $h$ represents particular scheduling slot. Let $\lambda_{n}$ denote the probability that an appliance that is off at time $h$ is requested at time $h+1$. Both requests for shared power capacity and duration of time the appliance is still on are random. A schedulable appliance a from residence $n$ sends a request at time slot $h$ to the smart meter to run a load rated $x_{n, a}$ with comfort level $d_{n, a}$. The comfort level represents a maximum amount of scheduling slots that a consumer is willing to wait for the appliance to run. The comfort level of 0 means a user wants the load to be connected right away-no scheduling. To account for green energy and storage, an equation proposed in [24], is modified such that a decision to run the appliance right away or defer it is done based on Equation (7). If an appliance is turned on at time $h$, the probability that it will still be on at time $h+1$ is $\mu_{i}$. We assume an event that particular appliance is on at time $h$ is independent of the event that the same appliance is on at time $h+1$.

$$
f(s)=(s-h) * \phi_{a}+\sum_{r=s}^{H}\left(\prod_{i=s}^{r-1}\left(1-\mu_{i}\right)\right) *\left(\Delta_{h, n} * c_{h}+W_{h, n}\right)
$$

In Equation (7), $s$ is the starting time of the appliance, where $h \leq s \leq h+d_{n, a}$. So the first term indicates cost associated with waiting for the appliance to run. $\phi_{a}$ is the cost of waiting for particular elastic appliance. The second term is the expected cost if the appliance is on. $\Delta_{h, n}$ is net electricity consumed from the grid by residence $n$ and its price is $c_{h} . W_{h, n}$ is the wearing cost of residence $n$ 's the PV system and storage during control period. According to Equation (7), the cost of running a certain appliance increases with increase in waiting time, net electricity consumed from the grid, or total running time of the appliance. Likewise, the cost decreases with decrease in waiting time, net electricity consumed from the grid, or total running time of the appliance.

$$
\begin{aligned}
& \Delta_{h, n}=\left\{\begin{array}{l}
x_{n, a} \text { if } R_{n}=0 ; \\
0 i f\left(B_{h, n}-\left(1 / \eta_{d} * x_{n, a}\right)-B_{\min , n}\right) \geq x_{n, a} ; \\
\left(x_{n, a}-\left(B_{h, n}-\left(1 / \eta_{d} * x_{n, a}\right)-B_{\min , n}\right)\right), \text { otherwise }
\end{array}\right. \\
& W_{h, n}=\left\{\begin{array}{l}
0 \text { if } R_{n}=0 ; \\
\sum_{h=s}^{H}\left[q *\left(x_{a, n}-\Delta_{h, n}\right)\right]+(H-s) * b, \text { otherwise }
\end{array}\right.
\end{aligned}
$$

In Equation (8) and Equation (9); $\mathrm{R}_{\mathrm{n}}$ is a binary variable with a value of 0 if a residence has no green energy and 1 otherwise. In Equation (9), $q$ is the storage wearing coefficient and $b$ represents hourly wearing coefficient of other PV components. Equation (8) means electricity is wholly drawn from the grid if the consumer has no GES. Otherwise, electricity is fully or partly drawn from GES. This means as the size of storage and quality of PV increases, more electricity will be drawn from it, while poor GES system means more grid electricity will be consumed. Equation (9) implies that consumers without GES do not incur costs 
associated with its wear and tear, whilst those who have GES incur those cost depending on how long they run the appliance.

\section{Consumption Scheduling}

Hourly maximum power capacity is shared throughout a community so as to exploit heterogeneity of consumers to implement a DSM program. Employing a token based algorithm, every consumer is guaranteed to access a token at least once in every scheduling slot. A Coordinator unit housed at a transformer unit manages the tokens. The Coordinator receives price and power capacity constraints information from a utility company and communicates them to the entire community using the token. The token holds information about hourly prices, hourly maximum capacity and hourly instantaneous consumed power.

Consumers in the community need no token to run their fixed appliances, however their loads contribute towards maximum power capacity. For inelastic appliances, consumers can run them directly if they have sufficient stored power; otherwise, they have to wait for the token. Algorithm 1 illustrates an access guaranteed and green-Aware token based consumption Scheduling Algorithm.

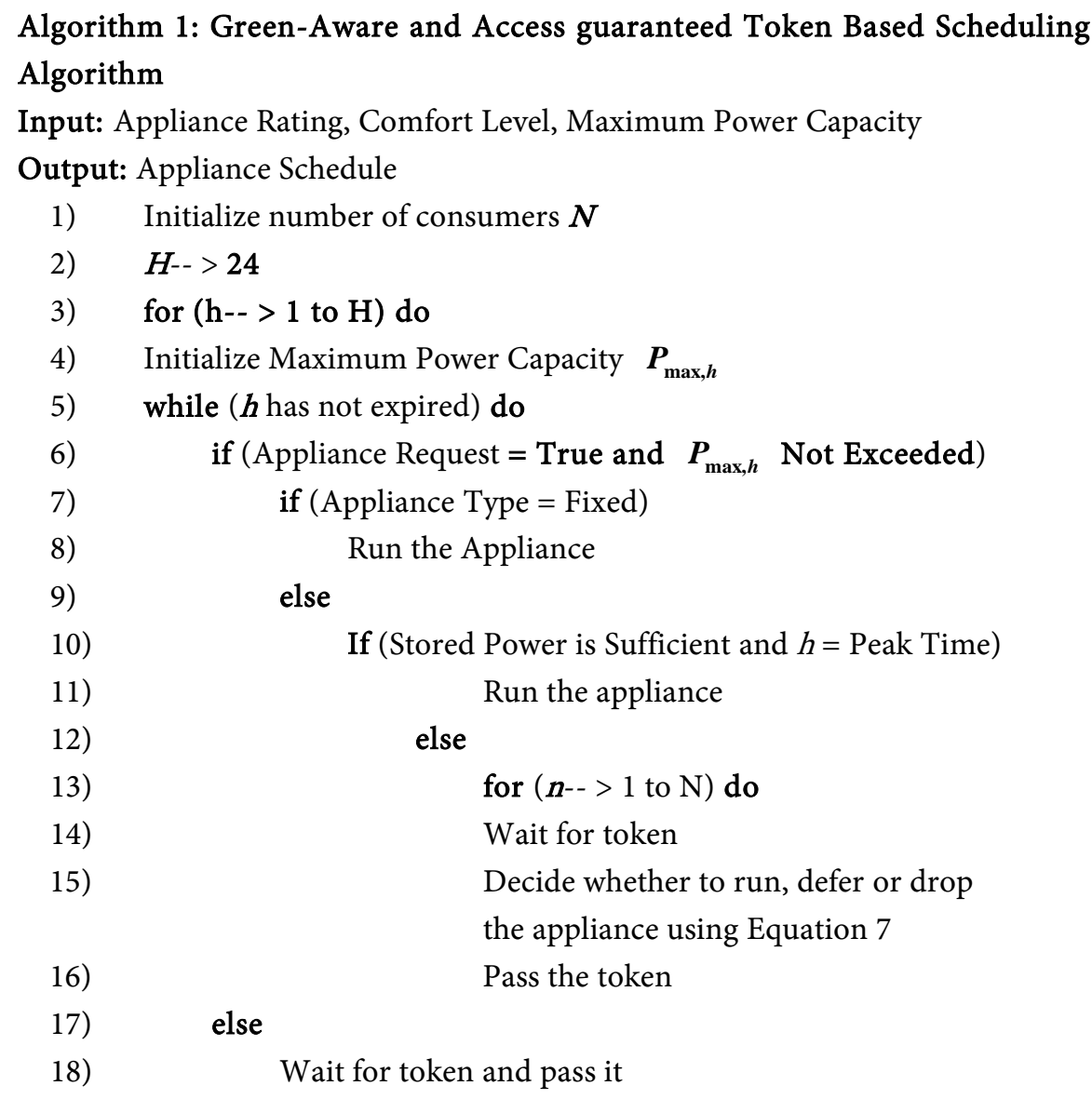

\section{Numerical Study}

For the sake of legibility and clarity of figures, a community with 10 residences $(N=10)$ has been considered. Actual Time of Use (ToU) prices from Con Edi- 
son-an energy company in New York, have been used [34]. ToU pricing used in this work divides a day into two parts: off-peak period (from 2300 hrs to 0900 hrs) and peak period (1000 hrs to $2200 \mathrm{hrs).} \mathrm{Price} \mathrm{of} \mathrm{electricity} \mathrm{for} \mathrm{off-peak} \mathrm{pe-}$ riod is $\$ 0.014 / \mathrm{kWh}$, while that of peak period is $\$ 0.21 / \mathrm{kWh}$. Hourly maximum shared power capacity is $40 \mathrm{KW}$ as in [24]. Self-generation, particulary solar power based generation is on the rise worldwide and it accounts for $6 \%-20 \%$ of total generation [35]. While self-generation in developed countries is largely fueled by environmental concerns, in developing countries it is triggered by insufficient generation capacity or unreliability of power. Acquiring GES systems in developing countries such as Tanzania is flexible enough such that customers have an opportunity to choose prepaid or postpaid payment plan. Based on these facts, it has been assumed $50 \%$ of residences in the community have GES and Storage with varying capacities. Table 1, Table 2 and Table 3 shows parameters for Elastic appliances and their associated consumption patterns as suggested in [24], fixed appliances proposed by [33], and both PV and storage, based on studies by [18] [36] [37], respectively.

Figure 2 shows each residence's access to shared maximum power capacity at different hours. All residences in the community have access to shared maximum power capacity, regardless of whether they have GES and storage or not. Each residence is guaranteed access to shared capacity at least once during each scheduling slot.

Total consumption of GES in the community is shown in Figure 3. The proposed algorithm schedules appliances to consume stored power during peak hours only-specifically, starting from $1800 \mathrm{hrs}$. It is assumed charging of the storage happens during daytime; therefore charging and discharging are not happening concurrently.

Table 1. Elastic appliances.

\begin{tabular}{cccc}
\hline Parameters & Washer & Drier & Heater \\
\hline$x_{n, a}$ & 1.8 & 3.4 & 5.0 \\
$d_{n, a}$ & 6 & 4 & 2 \\
$\phi_{\mathrm{a}}$ & 0.10 & 0.25 & 0.40 \\
$\min \lambda_{n}$ & 0.01 & 0.0392 & 0.0952 \\
$\max \lambda_{n}$ & 0.0704 & 0.1193 & 0.2078 \\
$\mu_{\mathrm{i}}$ & 0.283 & 0.632 & 0.865
\end{tabular}

Table 2. Fixed appliances.

\begin{tabular}{cc}
\hline Appliance & Rating \\
\hline Television & 0.20 \\
Computer & 0.35 \\
Indoor Lighting & 0.36 \\
Refrigerator & 0.50 \\
\hline
\end{tabular}


Table 3. Storage and PV.

\begin{tabular}{cc}
\hline Parameter & Value \\
\hline$\eta_{c}$ & $85 \%$ \\
$\eta_{d}$ & $100 \%$ \\
DOD & $70 \%$ \\
$B_{\max , n}$ & $5-8 \mathrm{kWh}$ \\
$I_{p v, h}($ Africa $)$ & $1 \mathrm{~kW} / \mathrm{m}^{2}$ \\
$S_{p v, n}$ & $7.6-20.7 \mathrm{~m}^{2}$ \\
$\eta_{p v}$ & $16 \%$ \\
\hline
\end{tabular}
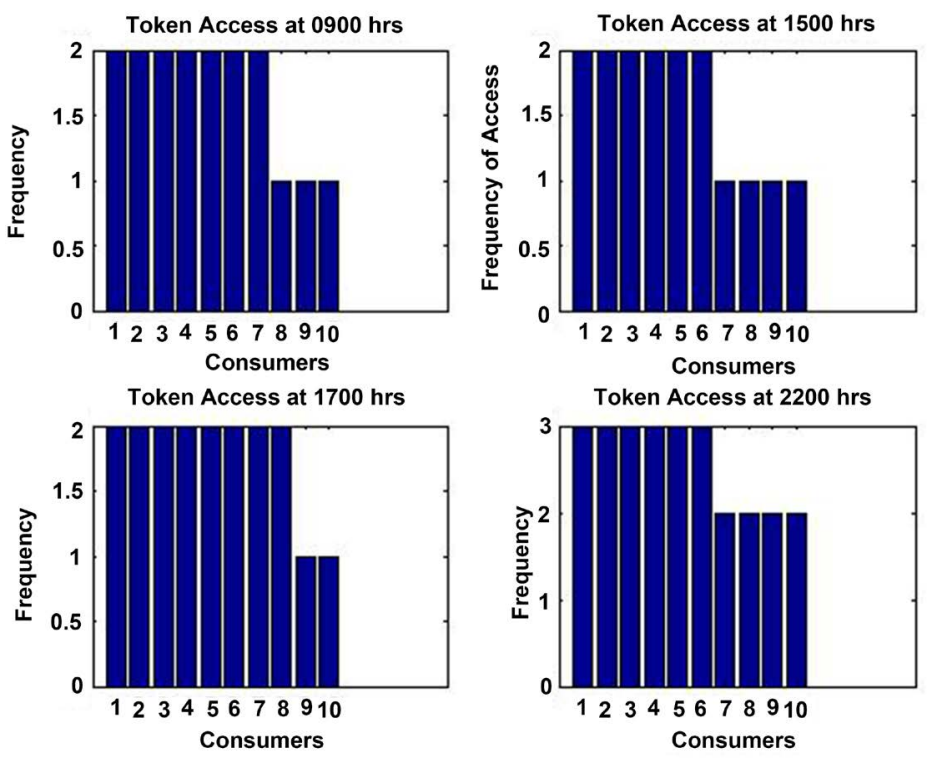

Figure 2. Access to shared capacity.

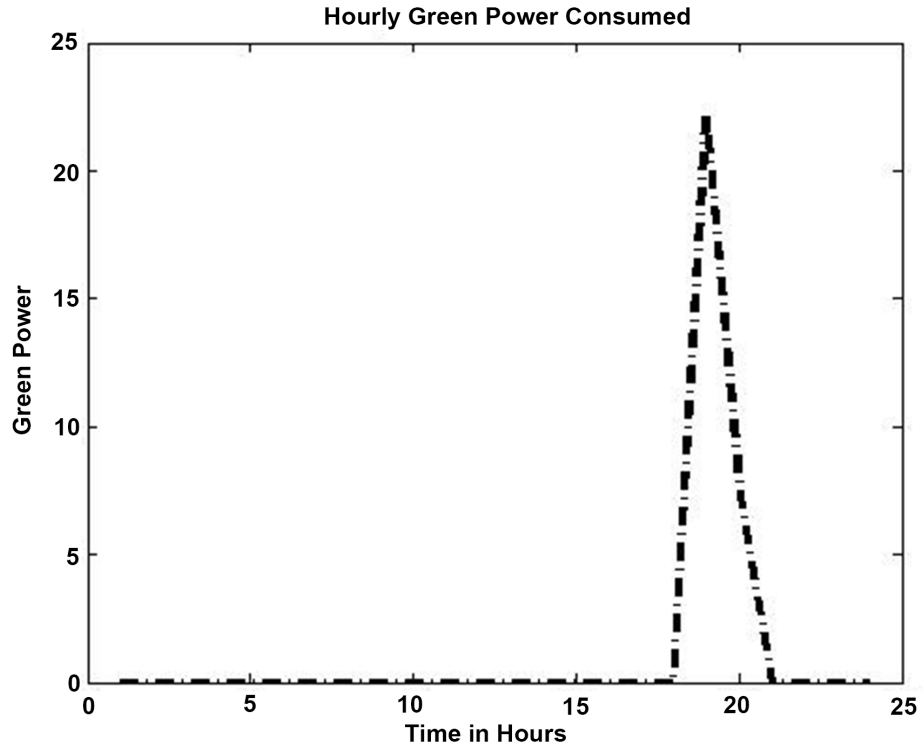

Figure 3. Green power consumed. 
Figure 4 indicates power consumed from the grid which has PAR value of 1.018. Figure 5 shows total consumption of power in the community (green and grid power) with PAR $=1.50$. From Figure 4 and Figure 3 it can be observed that GES and Storage can reduce grid's peak demand by up to $32.1 \%$ without entirely relying on shifting consumption and hence reduce energy cost by up $14 \%$.

While DSM works by shifting demand from peak hours to off-peak, Figure 6 indicates loads shifted to 2000 hours and 2300 hours. Based on applied ToU pricing, 2000 hours is in peak hours and 2300 hours is in off-peak hours. Likewise, Figure 7 indicates loads shifted to 1800 hours, 2100 hours and 2300 hours. 1800 hours and 2100 hours are peak hours and 2300 hours is off-peak hour. Both figures, this occurs when electricity is drawn from both grid and GES.

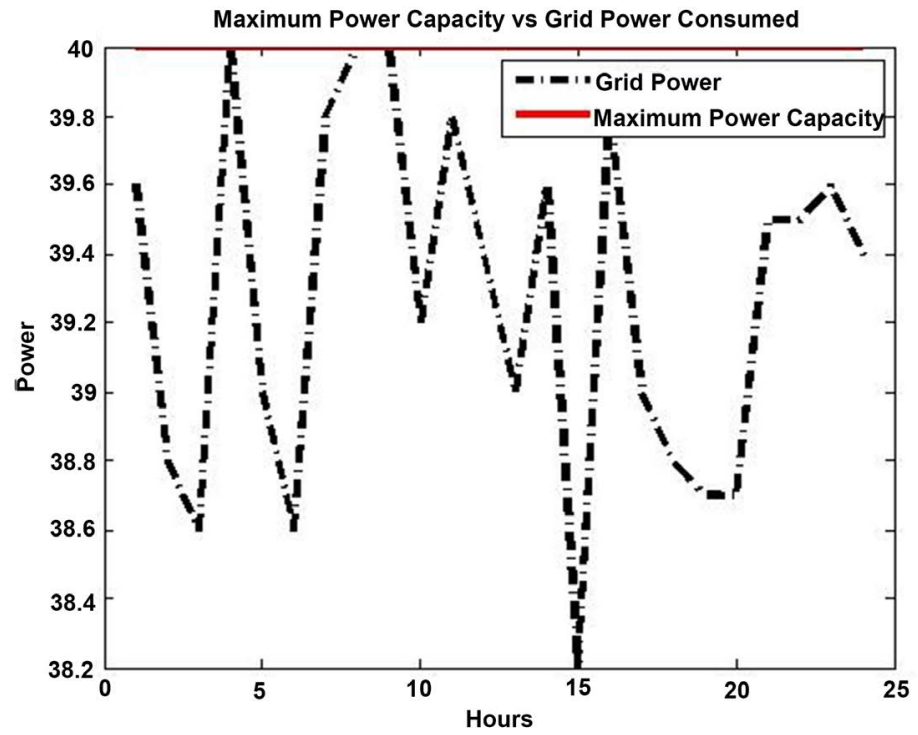

Figure 4. Power consumed from the grid.

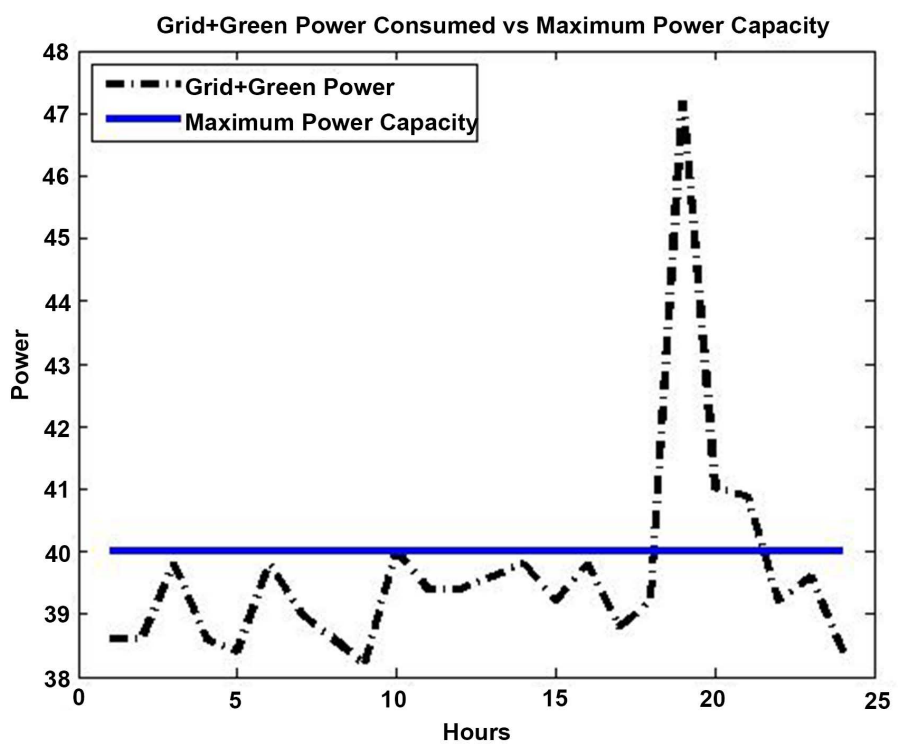

Figure 5. Total consumed power (grid + green). 


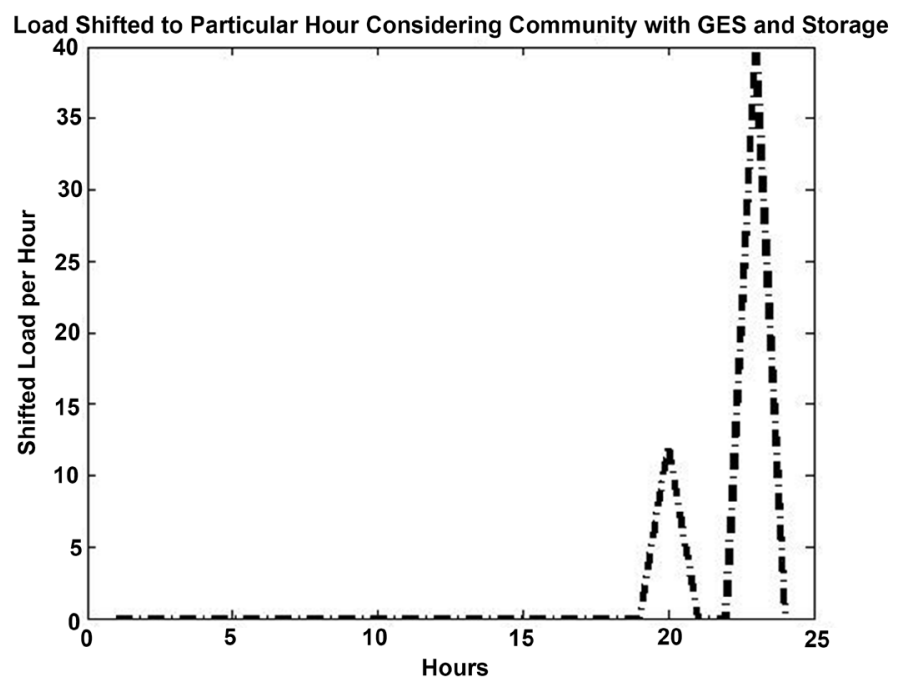

Figure 6. Two reverse peaks.

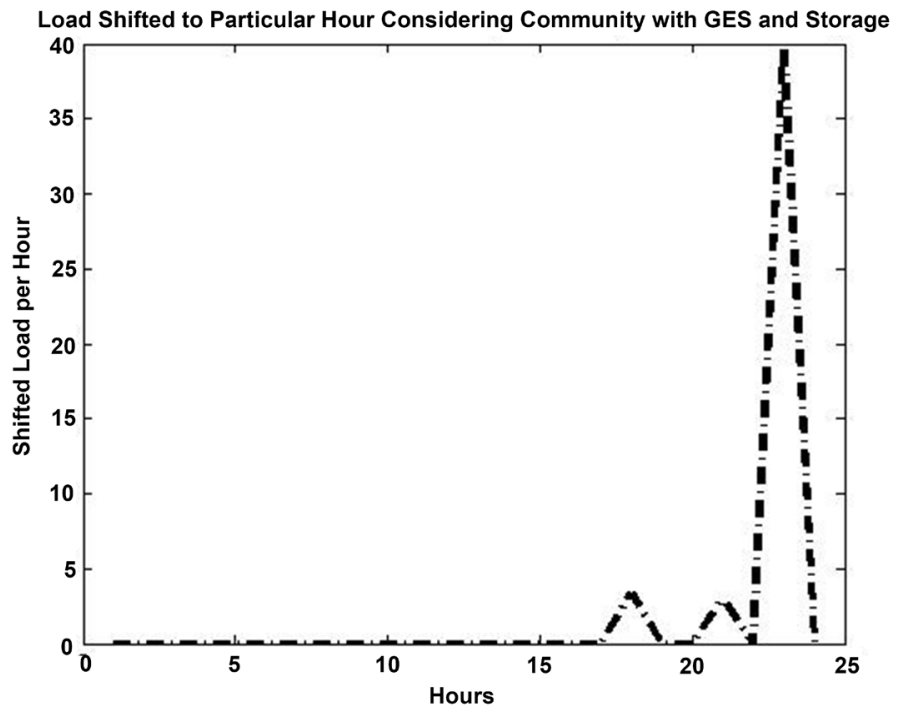

Figure 7. Three reverse peaks.

There are times when only a fraction of requested load can be run using energy stored in batteries, so the rest of the energy has to be drawn from the grid. But since electricity drawn from grid is subject to capacity constraints, if maximum capacity is reached, then the remaining fraction that has to be drawn from the grid is shifted to next hour so as to reduce inconveniences for the consumer with GES. This enables utilities to spread shifted loads over several hours and thereby mitigate reverse peaks and avoid dropping loads when total shifted loads exceed maximum capacity constraints. For instance, in Figure 6, load shifted to 2000 hours $(12.1 \mathrm{KW})$ is $23.4 \%$ of total shifted. Without GES, this load would be dropped if there was a capacity constraint or cause an even higher reverse peak if there was no capacity constraint because all of it would be shifted to 2300 hours which is off-peak hour as in Figure 8. 


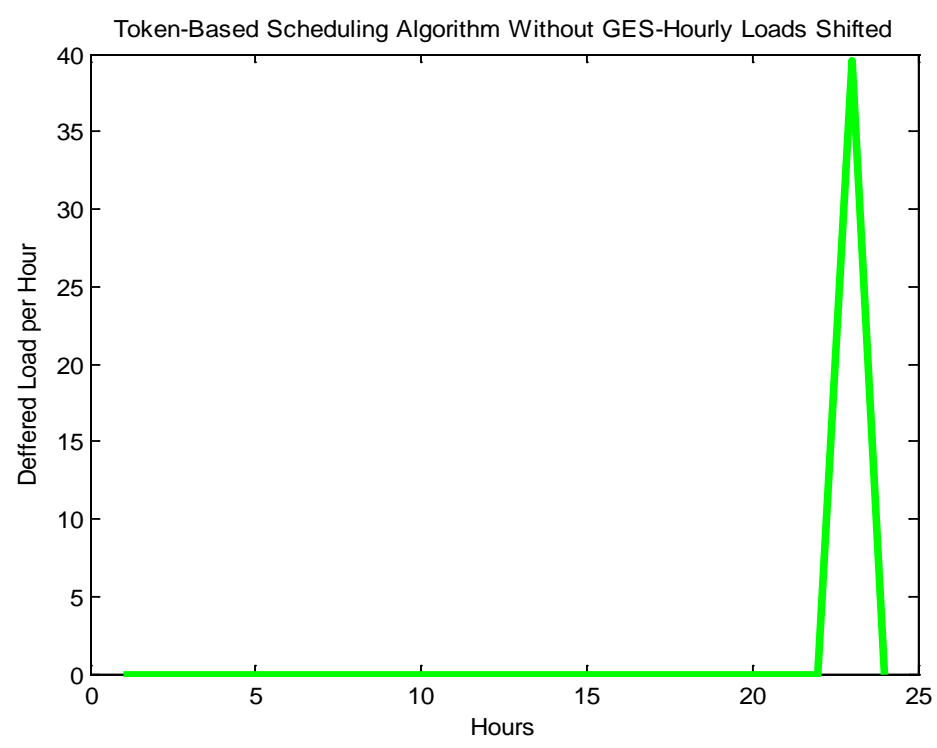

Figure 8. Token-based scheduling algorithm without GES-all deferred loads shifted to 2300 hours.

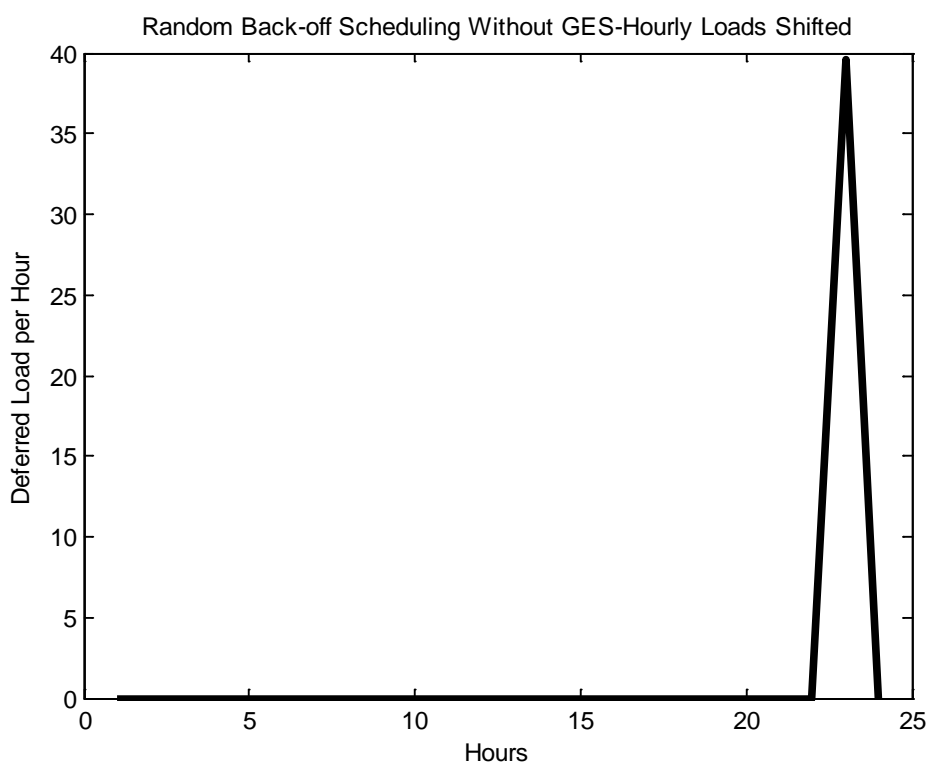

Figure 9. Random back-off algorithm without GES-all deferred loads shifted to 2300 hours.

Work by Kishore and Snyder [24] proposes a scheduling algorithm that is based on random back-off mechanism in order to share maximum capacity. Consumer have to wait random amount of time if it happens two or more of them are requesting shared capacity at the same time. While the algorithm results in comparable cost savings and PAR reduction with our proposed algorithm; it shifts all the loads to an hour right after peak hours-as it can be seen in Figure 9. With capacity constraint, some loads will be dropped if maximum hourly capacity is reached; otherwise, a reverse peak would occur-that is a highest peak occurring in previously off-peak hours. 


\section{Conclusion}

Community based DSM programs provides better opportunity to exploit consumption diversity and consequently reduce peak demand of electricity. Shifting load from peak to off-peak period can be a challenge to some consumers, hence exploiting rapidly growing PV Solar technology and integrating it with the grid leads to more flexible DSM programs. The green-aware and access guaranteed scheduling algorithm proposed in this work has the potential to reduce PAR and energy cost by up $27.7 \%$ and $14.0 \%$ respectively. Moreover, the algorithm can be used to mitigate reverse peaks by up to $23.4 \%$. Grid stability can be improved by encouraging and integrating distributed generation and storage of GES on the consumer side. This work can be extended to account for cases where consumers are able to sell extra energy to the grid and among them. Also, a shared GES in the community such as Wind farm and its storage can be studied.

\section{Acknowledgements}

We are gratefully to NM-AIST and Tanzania Government for funding this work.

\section{References}

[1] Darabi, Z. and Ferdowsi, M. (2011) Aggregated Impact of Plug-In Hybrid Electric Vehicles on Electricity Demand Profile. IEEE Transactions on Sustainable Energy, 2, 501-508. https://doi.org/10.1109/TSTE.2011.2158123

[2] Galus, M.D. and Andersson, G. (2008) Demand Management of Grid Connected Plug-In Hybrid Electric Vehicles (PHEV). Energy 2030 Conference, 2008. ENERGY 2008. IEEE, 1-8.

[3] Haney, A.B., Jamasb, T., Platchkov, L.M. and Pollitt, M.G. (2010) Demand-Side Management Strategies and the Residential Sector: Lessons from International Experience. http://www.dspace.cam.ac.uk/handle/1810/242085

[4] Pina, A., Silva, C. and Ferrão, P. (2012) The Impact of Demand side Management Strategies in the Penetration of Renewable Electricity. Energy, 41, 128-137. https://doi.org/10.1016/j.energy.2011.06.013

[5] Sieminski, A. (2014) International Energy Outlook. Energy Information Administration (EIA).

[6] Fang, X., Misra, S., Xue, G. and Yang, D. (2012) Smart Grid-The New and Improved Power Grid: A Survey. IEEE Communications Surveys \& Tutorials, 14, 944-980. https://doi.org/10.1109/SURV.2011.101911.00087

[7] Aalami, H., Moghaddam, M.P. and Yousefi, G. (2010) Modeling and Prioritizing Demand Response Programs in Power Markets. Electric Power Systems Research, 80, 426-435. https://doi.org/10.1016/j.epsr.2009.10.007

[8] Soliman, H.M. and Leon-Garcia, A. (2014) Game-Theoretic Demand-Side Management with Storage Devices for the Future Smart Grid. IEEE Transactions on Smart Grid, 5, 1475-1485. https://doi.org/10.1109/TSG.2014.2302245

[9] Kempener, R., d’Ortigue, O.L., Saygin, D., Skeer, J., Vinci, S. and Gielen, D. (2015) Off-Grid Renewable Energy Systems: Status and Methodological Issues. Abu Dhabi.

[10] Gelazanskas, L. and Gamage, K.A. (2014) Demand side Management in Smart Grid: A Review and Proposals for Future Direction. Sustainable Cities and Society, 11, 
22-30. https://doi.org/10.1016/j.scs.2013.11.001

[11] Khan, M., Javaid, N., Arif, M., Saud, S., Qasim, U. and Khan, Z. (2014) Peak Load Scheduling in Smart Grid Communication Environment. 28th International Conference on Advanced Information Networking and Applications, Victoria, 13-16 May 2014, 1025-1032. https://doi.org/10.1109/AINA.2014.135

[12] Meng, F.-L. and Zeng, X.-J. (2013) An Optimal Real-Time Pricing Algorithm for the Smart Grid: A Bi-Level Programming Approach. OASIcs-Open Access Series in Informatics.

[13] Bae, H., Yoon, J., Lee, Y., Lee, J., Kim, T., Yu, J., et al. (2014) User-Friendly Demand Side Management for Smart Grid Networks. International Conference on Information Networking, Phuket, 10-12 February 2014, 481-485.

[14] Goudarzi, H., Hatami, S. and Pedram, M. (2011) Demand-Side Load Scheduling Incentivized by Dynamic Energy Prices. IEEE International Conference on Smart Grid Communications, Brussels, 17-20 October 2011, 351-356. https://doi.org/10.1109/SmartGridComm.2011.6102346

[15] Holtschneider, T. and Erlich, I. (2012) Modeling Demand Response of Consumers to Incentives using Fuzzy Systems. Power and Energy Society General Meeting, San Diego, 22-26 July 2012, 1-8.

[16] Khan, M.A., Javaid, N., Mahmood, A., Khan, Z.A. and Alrajeh, N. (2015) A Generic Demand-Side Management Model for Smart Grid. International Journal of Energy Research, 39, 954-964. https://doi.org/10.1002/er.3304

[17] Wijaya, T.K., Papaioannou, T.G., Liu, X. and Aberer, K. (2013) Effective Consumption Scheduling for Demand-Side Management in the Smart Grid using Non-Uniform Participation Rate. Sustainable Internet and ICT for Sustainability, Palermo, 30-31 October 2013, 1-8.

[18] Wu, Z., Tazvinga, H. and Xia, X. (2015) Demand Side Management of Photovoltaic-Battery Hybrid System. Applied Energy, 148, 294-304.

https://doi.org/10.1016/j.apenergy.2015.03.109

[19] Huang, L., Walrand, J. and Ramchandran, K. (2012) Optimal Demand Response with Energy Storage Management. IEEE 3rd International Conference on Smart Grid Communications, Tainan, 5-8 November 2012, 61-66. https://doi.org/10.1109/SmartGridComm.2012.6485960

[20] Ruelens, F., Claessens, B., Vandael, S., De Schutter, B., Babuska, R. and Belmans, R. (2016) Residential Demand Response of Thermostatically Controlled Loads using Batch Reinforcement Learning. IEEE Transactions on Smart Grid, 1-11.

[21] Bakr, S. and Cranefield, S. (2013) Optimizing Shiftable Appliance Schedules across Residential Neighbourhoods for Lower Energy Costs and Fair Billing. AIH + CARE AUS-AI, 45-52.

[22] Barbato, A. and Capone, A. (2014) Optimization Models and Methods for Demand-Side Management of Residential Users: A Survey. Energies, 7, 5787-5824. https://doi.org/10.3390/en7095787

[23] Negeri, E. and Baken, N. (2012) Distributed Storage Management using Dynamic Pricing in a Self-Organized Energy Community. International Workshop on Self-Organizing Systems, 1-12. https://doi.org/10.1007/978-3-642-28583-7_1

[24] Kishore, S. and Snyder, L.V. (2010) Control Mechanisms for Residential Electricity Demand in Smartgrids. 1 st IEEE International Conference on Smart Grid Communications, Gaithersburg, 4-6 October 2010, 443-448.

[25] Mediwaththe, C.P., Stephens, E.R., Smith, D.B. and Mahanti, A. (2016) A Dynamic 
Game for Electricity Load Management in Neighborhood Area Networks. IEEE Transactions on Smart Grid, 7, 1329-1336. https://doi.org/10.1109/TSG.2015.2438892

[26] Mediwaththe, C.P., Stephens, E.R., Smith, D.B. and Mahanti, A. (2017) Competitive Energy Trading Framework for Demand-Side Management in Neighborhood Area Networks. IEEE Transactions on Smart Grid, 1.

[27] McDaniel, P. and McLaughlin, S. (2009) Security and Privacy Challenges in the Smart Grid. IEEE Security \& Privacy, 75-77. https://doi.org/10.1109/MSP.2009.76

[28] Zipperer, A., Aloise-Young, P.A., Suryanarayanan, S., Roche, R., Earle, L., Christensen, D., et al. (2013) Electric Energy Management in the Smart Home: Perspectives on Enabling Technologies and Consumer Behavior. Proceedings of the IEEE, 101, 2397-2408. https://doi.org/10.1109/JPROC.2013.2270172

[29] Mohsenian-Rad, A.-H., Wong, V.W., Jatskevich, J., Schober, R. and Leon-Garcia, A. (2010) Autonomous Demand-Side Management Based on Game-Theoretic Energy Consumption Scheduling for the Future Smart Grid. IEEE Transactions on Smart Grid, 1, 320-331. https://doi.org/10.1109/TSG.2010.2089069

[30] Hansen, U.E., Pedersen, M.B. and Nygaard, I. (2014) Review of Solar PV Market Development in East Africa. UNEP Risø Centre, Technical University of Denmark.

[31] Banu, I.-V. and Istrate, M. (2012) Modeling and Simulation of Photovoltaic Arrays. Buletinul AGIR, 3, 161-166.

[32] Bozchalui, M.C., Hashmi, S.A., Hassen, H., Cañizares, C.A. and Bhattacharya, K. (2012) Optimal Operation of Residential Energy Hubs in Smart Grids. IEEE Transactions on Smart Grid, 3, 1755-1766. https://doi.org/10.1109/TSG.2012.2212032

[33] Adika, C.O. and Wang, L. (2014) Smart Charging and Appliance Scheduling Approaches to Demand Side Management. International Journal of Electrical Power \& Energy Systems, 57, 232-240. https://doi.org/10.1016/j.ijepes.2013.12.004

[34] Belson, K. (2008) Lower Rates, But Not Until 10:00 PM. http://www.nytimes.com/2008/07/21/nyregion/21peak.html

[35] Foster, V. and Steinbuks, J. (2009) Paying the Price for Unreliable Power Supplies: In-House Generation of Electricity by Firms in Africa.

[36] Laboratory, N.R.E. (2017) PV Watts Calculator. http://pvwatts.nrel.gov/pvwatts.php

[37] Leadbetter, J. and Swan, L. (2012) Battery Storage System for Residential Electricity Peak Demand Shaving. Energy and Buildings, 55, 685-692. 